\begin{tabular}{|c|c|c|}
\hline $\begin{array}{l}\text { Editorial \& Publishing Offices : } \\
\text { MACMILLAN \& Co., LTD. } \\
\text { ST. MARTIN's STREET } \\
\text { LONDON, W.C.2 }\end{array}$ & & $\begin{array}{l}\text { Telegraphic Address : } \\
\text { PHusis, LESQUARE, LoNDON } \\
\text { Telephone Number : } \\
\text { WhITEHALI 883I }\end{array}$ \\
\hline No. 3539 & SATURDAY, AUGUST 28, 1937 & Vol. I40 \\
\hline
\end{tabular}

\title{
International Co-operation in Science
}

$T^{1}$ $\mathrm{HE}$ organization of international co-operation must in the nature of things be very different in different branches of science. Thus in astronomy, where no one country can cover the whole of the heavens or observe the sun continually through the twenty-four hours of the day, progress in many branches of statistical and even observational astronomy must depend on observers working in many countries of the globe on mutually agreed programmes. In geodesy the shape of the earth can only be determined with the highest possible accuracy by the survey of long arcs passing through a number of countries. Meteorology, geography and radio-science similarly present obvious examples where international agreements can alone secure the maximum of beneficial results from separate sets of observations and from instrumental and theoretical developments.

On the other hand, in sciences such as physics, chemistry and the biological sciences, where most developments come from the individual investigator and his team of co-workers, the value of international organization is less obvious, being limited at first sight to such important questions as the definition of standards or agreements on nomenclature. These have become the care of International Unions or International Congresses. The organized Union is to be preferred for such work to the Congress, as its framework is on the whole more suited to the maintenance of permanent committees. Both Unions and Congresses fulfil one further purpose of great value in bringing together periodically for discussion and mutual intercourse fellow-workers from many scattered lands, studying a group of cognate subjects. A similar service on a more limited scale is served by the gatherings of specialists in a given field of work held from time to time at various academic centres.
The International Council of Scientific Unions, heir to the old Association of Academies, serves as a link between the chief scientific bodies of the nations and also as a link between the various International Unions that adhere to it. One of its most useful tasks is to organize committees for the study of problems in which a number of Unions are interested: the Committee on Solar and Terrestrial Relationships examines just such a set of problems ; the Unions of Astronomy, of Geodesy and Geophysics and of Radio-Science are all interested in its work and nominate members to serve on it.

The International Council may be said to approach the question of international co-operation from the side of the Unions. Another body, the Organisation Internationale de Co-opération Intellectuelle de la Société des Nations, working through its committee of scientific experts, has had quite another line of approach. It may be said to look at scientific questions from the points of view of those familiar with the problems that daily face the League of Nations. Thus the question of organizing help for scientific bodies of undoubted international value that for financial reasons find themselves unable to continue with their work comes naturally to the Organisation. Or again, the publication of important learned papers in languages not widely diffused in the world- - a question of importance to scientific workers but not to them alone-has been studied by the Organisation, and a solution is more likely to be reached by the channels to which it has access than by individual Unions or Congresses or even the International Council. The same is true of the question of unauthorized translations of scientific work, and of the co-ordination of funds available in different countries for special 
researches-a co-ordination necessary in order to avoid unnecessary or undesirable overlapping.

After some years of negotiations, the International Council of Scientific Unions and the Organisation Internationale de Co-operation Intellectuelle have come to an agreement to work together in the several tasks which they facenot as one body but as two bodies in close touch with each other. Last month, in Paris, at a joint meeting of the two bodies (see Nature, July 17, p. 121), Prof. Ch. Fabrv and Sir Gilbert Murray signed an agreement which lays down the method of co-operation of the two bodies, the respective spheres of action being broadly along the lines indicated above. Purely scientific questions will go to the Council, which will work through its constituent Unions: questions of a primarily international nature will be referred to the Organisation. At a recent meeting of the General Assembly of the International Council a proposal was made for the appointment of a committee on the relation of science to the life of the community. It was pointed out that in its original form this motion covered a field lying beyond the purview of the Council. In the amended form which was adopted, the work of the Committee, which has now been appointed (see p. 358), was limited to the scientific side of the question. The more political side may be taken up elsewhere, and represents the kind of question that may fall to the Organisation to study.

There remain gaps on both sides. Subjectsgeology and mathematics may be mentioned-lie outside the range covered by the Council ; countries stand aloof from the League of Nations. Still, the rapprochement between the two bodies can but strengthen both and may lead to more active co-operation between them and those other bodies which stay outside, though each is carrying out work of similar purpose in its own branch of science.

\section{Native Science in Southern Sudan}

\section{Witchcraft, Oracles and Magic among the Azande}

By Dr. E. E. Evans-Pritchard. Pp. $x x x+558+34$ plates. (Oxford: Clarendon Press; London: Oxford University Press, 1937.) 21s. net.

$\mathrm{D}^{\mathrm{R}}$ R. E. E. EVANS-PRITCHARD, already well known in anthropological circles for some penetrating studies of the manners, customs and mental constitution of certain peoples of the AngloEgyptian Sudan, has by this book placed himself in the front rank of British anthropologists. Europeans who have visited primitive people have always been attracted by the notions which they think they have found concerning witehcraft, oracles and magic; but most of them have attempted to interpret these notions mainly in the light of their own, or what they consider to be their own, habits of thought. Consequently, these topics have been treated as if their main interest lay in their curiosity, their oddity; and not infrequently they have been taken to indicate that there is some sort of primitive logic exceedingly different from that of the Western world. Dr. Evans-Pritchard is no mere curiosity hunter; he realizes that many of the Azande notions about witchcraft, and the ways in which the people use them, are not far removed from some of our own current ideas and practices about medicine and the chances of life; and he knows perfectly well that though his book is entirely concerned with witches, witch-doctors, magicians and sorcerers, it covers only a very small part of Azande activity: "Most of their talk is common-sense talk, and their references to witchcraft, whilst frequent enough, bear no comparison in volume to their talk about other matters".

The Azande are a fairly numerous people living on the Nile-Congo divide. At present they form a homogeneous group, but they were formerly of many different tribes, with a variety of languages and institutions. As is natural, in such circumstances differences of social status play a great part in Zande culture. In particular, while the general rank and file are easily accessible; sociable, good-natured, assimilative, the royal class remain aloof, conservative, superior.

"Every Zande is an authority on witcheraft." If anything unusual happens, especially anything of an unfortunate character, it is attributed to some person-less often to some animal-in whom witchcraft resides as an inherent quality. This person does not need to do anything special in order to exert his influence; in fact, he cannot well help himself, for within him, whether he knows it or not, is some "witchcraft substance". Dr. Evans-Pritchard has himself never seen this substance, but it can be discovered by autopsy, and the evidence leads him to believe that it is the small intestine at a certain phase of digestive process. 